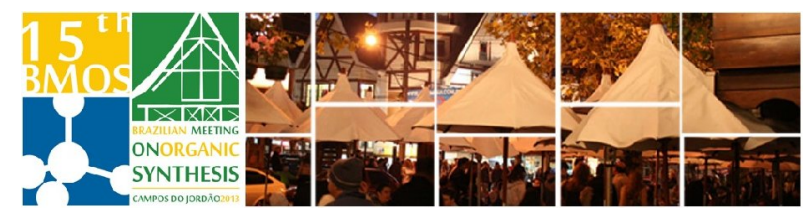

\title{
Substrate-controlled Asymmetric Morita-Baylis-Hillman Reaction: an Approach to the Synthesis of Pyrrolizidinones and Pyrrolizidines
}

\author{
João P. S. Scaramal, Kristerson R. Luna-Freire, and Fernando Coelho* \\ Laboratory of Synthesis of Natural Products and Drugs, University of Campinas - PO Box 6154 - 13083- \\ 970 - Campinas, SP - Brazil; \\ *coelho@iqm.unicamp.br
}

Keywords:Morita-Baylis-Hillman, Heterocycles, Pyrrolizidines

\section{INTRODUCTION}

The hexahydro-pyrrolizidine skeleton is a structural motif found in several biologically active compounds. The pyrrolizidinic alkaloids are a good example of compounds isolated from natural sources which exhibited this motif in their structures and remarkable biological effects. ${ }^{1}$

The biological relevance of these compounds justifies the development of new approach to them. We disclose herein a facile and fast approach to the synthesis of poly-hydroxylated pyrolizidinones and pyrrolizidines using Morita-Baylis-Hillman adducts as substrate. ${ }^{2}$

\section{RESULTS AND DISCUSSION}

In order to obtain our target compounds, we carried out a $\mathrm{MBH}$ reaction with substituted prolinal. So, (4R)-hydroxy-(2S)-prolinal (1) was submitted to a $\mathrm{MBH}$ reaction to give adducts 2 and $\mathbf{3}$, as a mixture of diastereoisomers (4:1). After separation, both diastereoisomers were treated with concentrated $\mathrm{HCl}$ solution and water to provide hydroxylated pyrrolizidinones $\mathbf{4}$ and $\mathbf{5}$ (Scheme 1).

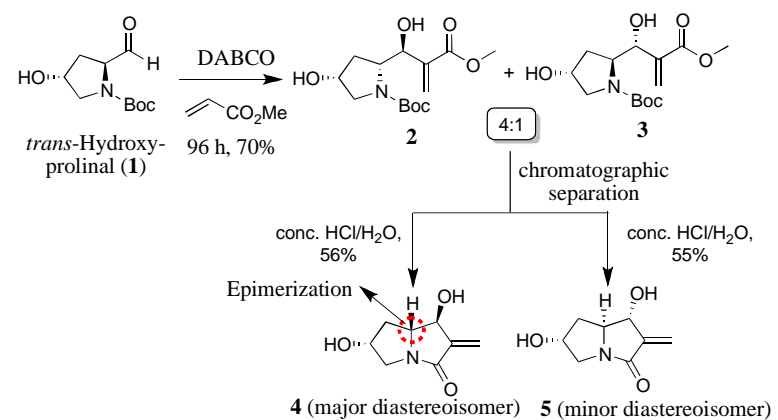

Scheme 1. Synthesis of pyrrolizidinones from MBH adducts

This result can only be explained if racemization had occurred during the Morita-Baylis-Hillman. Searching to understand this behaviour, we decided to determine if the hydroxyl group at C3 had some influence in this process. Both enantiomer of cishydroxy prolines (+)-6a and (-)-6b were used as substrate for another $\mathrm{MBH}$ reaction. In both cases, a unique diastereoisomer was detected. Most probably, an intramolecular hydrogen bond (only possible on the cis-isomer) can explain these $15^{\text {th }}$ Brazilian Meeting on Organic Synthesis $-15^{\text {th }}$ results. The double bond of compound $\mathbf{7}$ and $\mathbf{4}$ were ozonolyzed, followed by in situ stereoselective reduction to provide pyrrolizidinones, as a sole product.

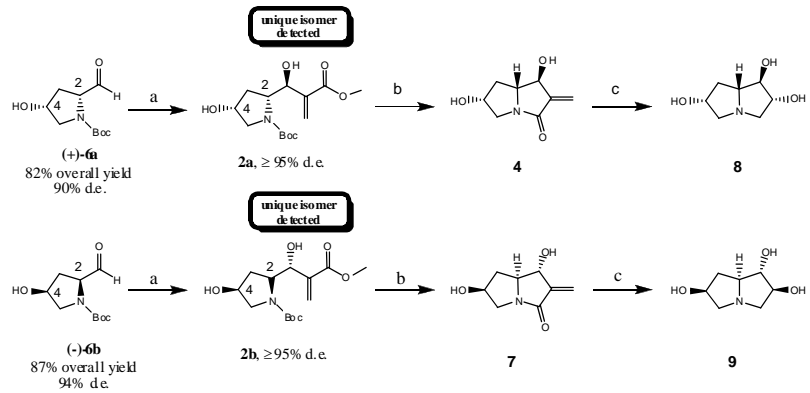

Scheme 2. Reagents and conditions: a) metyl acrylate, $\mathrm{DABCO}$, $96 \mathrm{~h}, 70-76 \%$; b) conc. $\mathrm{HCl} / \mathrm{H}_{2} \mathrm{O}, 55-60 \%$. Proving the role displayed by hydroxyl group at $\mathrm{C} 3$. c) $\mathrm{O}_{3}, \mathrm{CH}_{2} \mathrm{Cl}_{2}: \mathrm{MeOH}$ (8:2), $78{ }^{\circ} \mathrm{C}, 10 \mathrm{~min}$; ii. $\mathrm{NaBH}_{4},-78{ }^{\circ} \mathrm{C}$ to r.t., $4 \mathrm{~h}, 78 \%$. ) $\mathrm{AlH}_{3}(17$ equiv.) $\left(\mathrm{AlCl}_{3}: \mathrm{LiAlH}_{4}, 1 \mathrm{~mol} / \mathrm{L}\right)$, THF, reflux, $3 \mathrm{~h}, 75-80 \%$; Synthesis of poly-hydroxylated pyrrolizidines.

Pyrrolizidinones were treated with $\mathrm{AlH}_{3}$ to give polyhydroxylated pyrrolizidines 8 and $\mathbf{9}$, in 80 and $75 \%$ yield respectively. Compounds 8 and 9 were synthesized in 5 steps with an overall yield of 24 and $20 \%$, respectively.

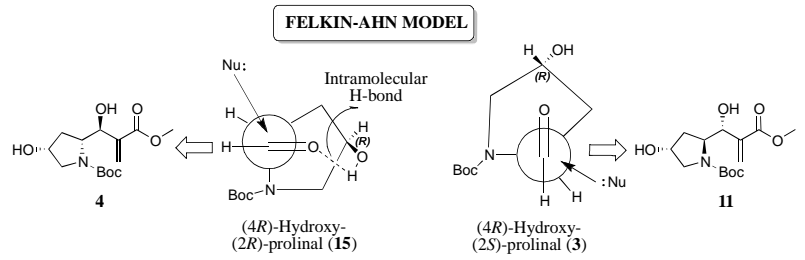

Figure 1. Rationalizing our results.

\section{CONCLUSION}

An asymmetric substrate-controlled Morita-Baylis-Hillman reaction allowed the synthesis pyrrolizidinones and pyrrolizidines in few steps and good overall yield.

\section{ACKNOWLEDGEMENTS}

We thank FAPESP, CNPq and CAPES for financial support.

\section{REFERENCES}

${ }^{1}$ Reddy, P. V.; Veyron, A.; Koos, P.; Bayle, A.; Greene, A. E. Delair, P. Org. Biomol. Chem. 2008, 6, 1170-1172

2 Luna-Freire, K. R.; Tormena, C. F.; Coelho, F. Synlett 2011, 2059-2063 urtis, M. D.; Shiu, K.; Butler, W. M. e Huffmann, J. C. J. Am. Chem. Soc. 1986, 108, 3335. 